\title{
Anaemia among pregnant Palestinian women in the Occupied Palestinian Territory
}

\author{
A Khader ${ }^{1}, \mathrm{H} \mathrm{Madi}^{2}, \mathrm{~F} \mathrm{Riccardo}^{3, *}$ and G Sabatinelli ${ }^{3}$ \\ ${ }^{1}$ Health Protection and Promotion, United Nations Relief and Works Agency for Palestine Refugees in the Near \\ East (UNRWA), Health Department HQ, Bayader Wadi Seer, PO Box 140157, Amman 11814, Jordan: ${ }^{2}$ Health \\ Protection and Promotion, WHO Regional Office for the Eastern Mediterranean, Cairo, Egypt: ${ }^{3}$ UNRWA, Health \\ Department $\mathrm{HQ}$, Amman, Jordan
}

Submitted 7 January 2008: Accepted 5 February 2009: First published online 14 August 2009

\begin{abstract}
Objective: To assess anaemia prevalence and correlated social and biological determinants among pregnant women in the Occupied Palestinian Territory (oPt). Design: A cross-sectional survey conducted among pregnant women attending/ accessing UNRWA (United Nations Relief and Works Agency for Palestine Refugees in the Near East) health centres in the Gaza Strip and the West Bank in September and October 2006.

Setting: Fifty-five UNRWA health centres in the oPt (eighteen in the Gaza Strip and thirty-seven in the West Bank).

Subjects: A random sample of 1740 pregnant women.

Results: Overall anaemia prevalence was 38.6\% (95\% CI 36.3, 40.9\%). A substantial difference in anaemia prevalence was observed between the Gaza Strip and the West Bank (44.9\% v. 31.1\%, respectively), as well as a significant increase in anaemia prevalence in the Gaza Strip compared with an Agency-wide survey conducted in 2004 ( $44.9 \%$ v. 35.7\%, respectively). Anaemia prevalence was found to increase with age, parity and trimester of gestation.

Conclusions: Anaemia still appears to be a public health problem among pregnant women in spite of UNRWA interventions. The West Bank shows prevalence rates similar to those observed in neighbouring countries, while the Gaza Strip has higher rates. Prevalence rates of anaemia among pregnant Palestinian women are more than two times higher than those observed in Europe.
\end{abstract}

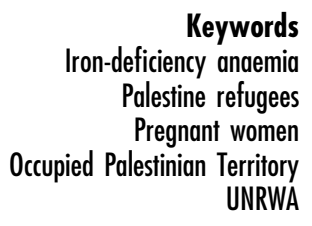

Food insecurity and malnutrition, which are common consequences of conflict and long-term socio-economic hardship, have emerged in the Occupied Palestinian Territory (oPt) since the year $2000^{(1)}$. According to the 2002 Nutritional Assessment of the West Bank and Gaza Strip, escalation of the Palestine-Israel conflict has led to 'a deterioration of the household economies, interfered with food availability and accessibility, and raised the probability of a significant problem of undernutrition'(2).

As observed in previous studies ${ }^{(3)}$, anaemia among Palestinian refugees is due essentially to the poor availability of dietary $\mathrm{Fe}$, and children and women are disproportionally affected. They are therefore the best group to monitor. Anaemia is a slow-onset consequence of micronutrient deficiency ${ }^{(4,5)}$; thus its prevalence might be linked to socio-economic conditions in the oPt in previous years.

The estimated anaemia prevalence among pregnant Palestinian refugee women in 1990 was $67 \cdot 4 \%$ in the Gaza Strip and $47 \cdot 6 \%$ in the West Bank $^{(6)}$. In 1999 the rates had decreased to $44.7 \%$ in the Gaza Strip and $35.5 \%$ in the West $\operatorname{Bank}^{(7)}$. The aim of the present paper is to

describe the current prevalence of anaemia among pregnant women in the oPt, correlating the findings with social and biological determinants.

\section{Experimental methods}

\section{Study setting}

The study was conducted in September and October 2006 among registered pregnant Palestinian refugee women who attended UNRWA (United Nations Relief and Works Agency for Palestine Refugees in the Near East) antenatal clinics in the Gaza Strip and West Bank.

\section{Subjects}

UNRWA is the main health-care provider for the Palestine refugee population. It provides primary health care in 134 primary health-care facilities in Lebanon, Syria, the West Bank, the Gaza Strip and Jordan. Through its comprehensive antenatal and postnatal programme, it offers prevention and treatment of Fe-deficiency anaemia 
comprising supplementation and treatment with Fe and folic acid preparations, food supplementation, and fortification of wheat flour with Fe, folic acid and vitamins.

All pregnant women attending the UNRWA antenatal services were targeted for $\mathrm{Hb}$ testing and enrolled in the study from September 2006 until the sample size was reached. The catchment area comprised fifty-five UNRWA health centres in the oPt (eighteen in the Gaza Strip and thirty-seven in the West Bank).

\section{Data collection}

A data collection sheet was designed. Background information collected included age, education level, parity, trimester of gestation and interfamily marriage. Data were collected at the health centre level by staff nurses and compiled and validated by the Chief of the UNRWA Health Protection and Promotion Programme.

\section{Biochemical analysis}

$\mathrm{Hb}$ levels were determined using the cyanmethaemoglobin method. The cut-off point for anaemia was defined as $\mathrm{Hb}$ level below $11 \cdot 0 \mathrm{~g} / \mathrm{dl}$. Anaemia was further categorized as mild $(\mathrm{Hb}=9 \cdot 0-10 \cdot 9 \mathrm{~g} / \mathrm{dl})$, moderate $(\mathrm{Hb}=7 \cdot 0-8 \cdot 9 \mathrm{~g} / \mathrm{dl})$ and severe $(\mathrm{Hb}<7 \cdot 0 \mathrm{~g} / \mathrm{dl})^{(8)}$.

The study protocol was approved by the UNRWA Health Department Ethical Review Committee.

\section{Statistical methods}

Sample size was calculated using expected prevalence rates from an identically designed survey conducted by UNRWA in 2004 and defining a confidence level of 95\%, power of $80 \%$ and precision to the nearest $3 \%$.

The statistical significance of the association between anaemia and social and biological determinants was calculated using the $\chi^{2}$ test. $P$ values less than 0.05 were considered statistically significant.

Data were entered and analysed with the Epi Info ${ }^{\mathrm{TM}}$ for Windows statistical software package version $3 \cdot 4 \cdot 1$ (distributed by Centers for Disease Control and Prevention, Atlanta, GA, USA).

\section{Results}

The sampling frame consisted of 1740 pregnant women, randomly selected among those attending UNRWA antenatal services in the oPt. Mean age was $27 \cdot 1(\mathrm{SD} 6 \cdot 0)$ years, mean parity was $2 \cdot 7$ ( $\mathrm{SD} 2 \cdot 3$ ) live births and mean number of years of education was $10 \cdot 9$ (SD 3.1).

Anaemia prevalence in the oPt in 2006 was found to be $38.6 \%$ (95\% CI 36.3, 40.9\%). Most women (92.4\%) suffered from mild anaemia; the prevalence of moderateto-severe anaemia was 3\% (1.9\% in the West Bank and $4 \cdot 1 \%$ in the Gaza Strip).

The present survey showed a significant $\left(\chi^{2}=12 \cdot 9\right.$, $P<0 \cdot 01)$ overall increase in anaemia prevalence compared with $33 \cdot 2 \%$ reported in 2004 . However, once stratified by geographical area, the increase was statistically significant only for the Gaza Strip $\left(\chi^{2}=16 \cdot 8, P<0 \cdot 01\right.$; Table 1$)$.

Anaemia prevalence was found to increase with age, parity and trimester of pregnancy. The latter showed the strongest correlation with anaemia, with a threefold risk of developing the disease in the second and third trimesters of gestation as opposed to the first (second trimester $v$. first: $\mathrm{OR}=3 \cdot 2,95 \% \mathrm{CI} 2 \cdot 2,4 \cdot 6$; third trimester $v$. first: $\mathrm{OR}=3 \cdot 3,95 \% \mathrm{CI} 2 \cdot 2,4 \cdot 8)$. No statistical correlation was found between anaemia and level of education, interfamily marriage and residence in a camp, in both West Bank and Gaza Strip (Table 2).

Table 1 Anaemia prevalence among pregnant Palestinian women, 2004 and 2006

\begin{tabular}{lrrrrr}
\hline & \multicolumn{2}{c}{ Gaza Strip (\%) } & & \multicolumn{2}{c}{ West Bank (\%) } \\
\cline { 2 - 3 } \cline { 5 - 6 } & 2004 & 2006 & & 2004 & 2006 \\
\hline Severe $(\mathrm{Hb}<7.0 \mathrm{~g} / \mathrm{dl})$ & $0 \cdot 1$ & 0.0 & & 0.0 & 0.0 \\
Moderate $(\mathrm{Hb}=7 \cdot 0-8 \cdot 9 \mathrm{~g} / \mathrm{dl})$ & 3.0 & $4 \cdot 1$ & & 1.9 & 1.9 \\
Mild $(\mathrm{Hb}=9 \cdot 0-10 \cdot 9 \mathrm{~g} / \mathrm{dl})$ & 32.5 & 40.8 & & 27.6 & 29.2 \\
Overall anaemia & 35.7 & 44.9 & & 29.5 & 31.1 \\
\hline
\end{tabular}

Table 2 Association between anaemia and social and biological determinants among pregnant Palestinian women, 2006

\begin{tabular}{|c|c|c|c|}
\hline \multirow[b]{2}{*}{ Variable } & \multicolumn{2}{|c|}{ Prevalence of anaemia } & \multirow[b]{2}{*}{ Significance } \\
\hline & $\%$ & $n$ & \\
\hline \multicolumn{4}{|l|}{ Age (years) } \\
\hline $13-19$ & $25 \cdot 3$ & 40 & $\chi^{2}=24.5 ; P<0.01^{*}$ \\
\hline $20-24$ & $37 \cdot 0$ & 183 & \\
\hline $25-29$ & 38.5 & 200 & \\
\hline $30-34$ & $44 \cdot 6$ & 146 & \\
\hline $35-39$ & $45 \cdot 0$ & 85 & \\
\hline$\geq 40$ & $36 \cdot 8$ & 18 & \\
\hline \multicolumn{4}{|l|}{ Education } \\
\hline Illiterate & $62 \cdot 5$ & 10 & $\chi^{2}=0.01 ; P>0.05$ \\
\hline $1-6$ years & $39 \cdot 4$ & 52 & \\
\hline $7-9$ years & $38 \cdot 0$ & 150 & \\
\hline $10-12$ years & $38 \cdot 8$ & 323 & \\
\hline$\geq 12$ years & $37 \cdot 6$ & 137 & \\
\hline \multicolumn{4}{|l|}{ Parity } \\
\hline 0 & $30 \cdot 7$ & 92 & $\chi^{2}=11 \cdot 6 ; P<0.05^{*}$ \\
\hline $1-2$ & $36 \cdot 4$ & 233 & \\
\hline $3-4$ & $41 \cdot 7$ & 187 & \\
\hline $5-6$ & $43 \cdot 3$ & 100 & \\
\hline$\geq 7$ & $48 \cdot 8$ & 60 & \\
\hline \multicolumn{4}{|c|}{ Trimester of gestation } \\
\hline First & $20 \cdot 8$ & 85 & $\chi^{2}=46.0 ; P<0.01^{*}$ \\
\hline Second & $43 \cdot 7$ & 304 & \\
\hline Third & $44 \cdot 7$ & 283 & \\
\hline \multicolumn{4}{|c|}{ Interfamily marriage } \\
\hline First cousin & $39 \cdot 8$ & 129 & $\chi^{2}=1.5 ; P>0.05$ \\
\hline Second cousin & $42 \cdot 9$ & 57 & \\
\hline Relativet & $37 \cdot 0$ & 70 & \\
\hline Not related & $38 \cdot 1$ & 416 & \\
\hline \multicolumn{4}{|l|}{ Residence } \\
\hline Inside camp & $38 \cdot 1$ & 215 & $\chi^{2}=0.1 ; P>0.05$ \\
\hline Outside camp & $38 \cdot 9$ & 457 & \\
\hline
\end{tabular}

*Statistically significant correlation.

t'Relative' indicates any other person related by blood excluding first cousins (sons of siblings of the mother/father) or second cousins (sons of a first cousin of the woman's parent). 


\section{Discussion}

Anaemia among pregnant women in the oPt $38.6 \%$ prevalence) is a public health problem that can be classified as moderate in the West Bank $(31 \cdot 1 \%)$ and severe in the Gaza Strip $(44.9 \%)^{(9)}$.

The global prevalence of anaemia among pregnant women reported in the WHO 2007 survey among preschool children, pregnant women and non-pregnant women of reproductive age was $41 \cdot 8 \%$ (95\% CI 39.9, $43 \cdot 8)^{(10)}$. Analysing the global data disaggregated by UN region (Fig. 1) shows our surveyed population to have a prevalence of anaemia between the rates of Asia and Latin America and the Caribbean, with the highest rates observed in the Gaza Strip. Considering
Europe as the standard comparator, the prevalence of anaemia among pregnant Palestinian women is more than double.

Conversely, if we consider the prevalence rates of anaemia among pregnant women in countries of the Eastern Mediterranean Region as published by WHO in $2004^{(11)}$, only the West Bank has a prevalence rate that is in line with those observed in neighbouring countries. The Gaza Strip has a much higher prevalence (Fig. 2).

This might correlate with the worsening of socioeconomic conditions in the Gaza Strip in spite of UNRWA interventions. What can be inferred from the data presented is that if the social and economic situation in the oPt does not improve, anaemia rates among Palestine refugees could be subjected to future worsening ${ }^{(12)}$.

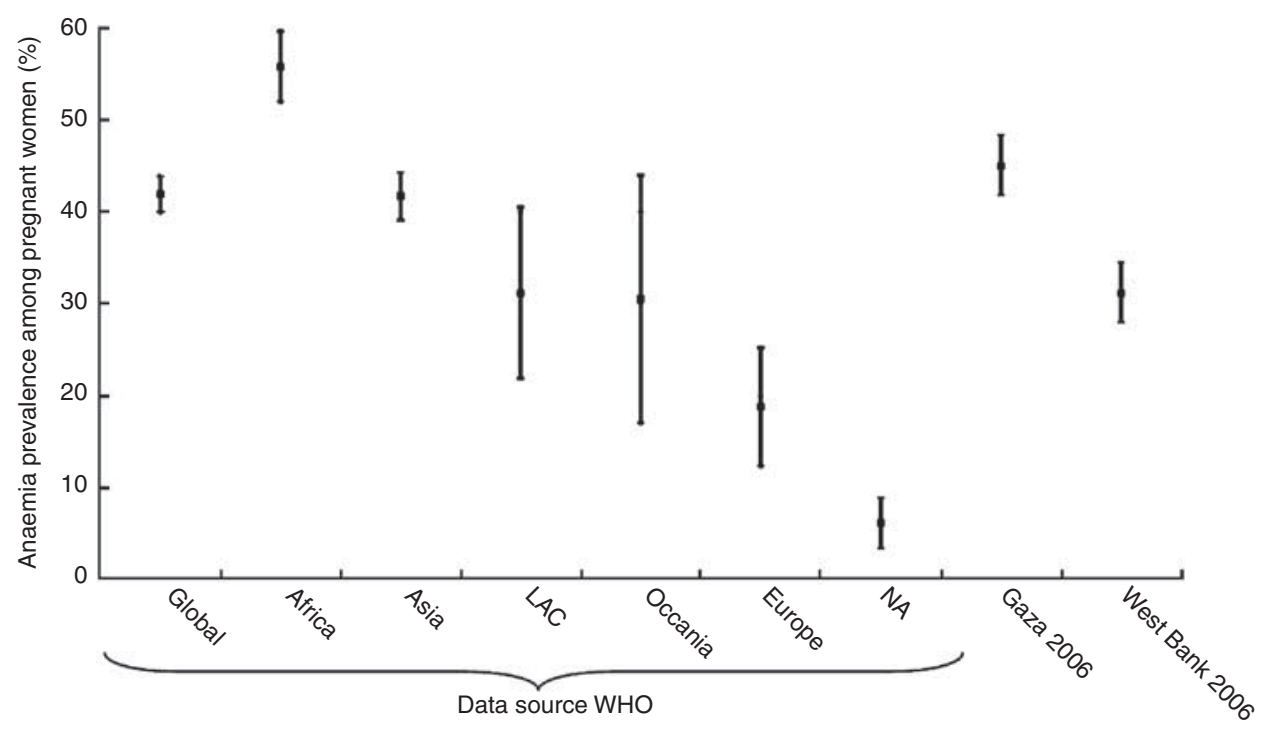

Fig. 1 Anaemia prevalence $(95 \% \mathrm{Cl})$ among pregnant women (LAC, Latin America and the Caribbean; NA, North America): comparison of data from the 2007 WHO global review ${ }^{(10)}$ and the present 2006 UNRWA (United Nations Relief and Works Agency for Palestine Refugees in the Near East) study in the Gaza Strip and the West Bank

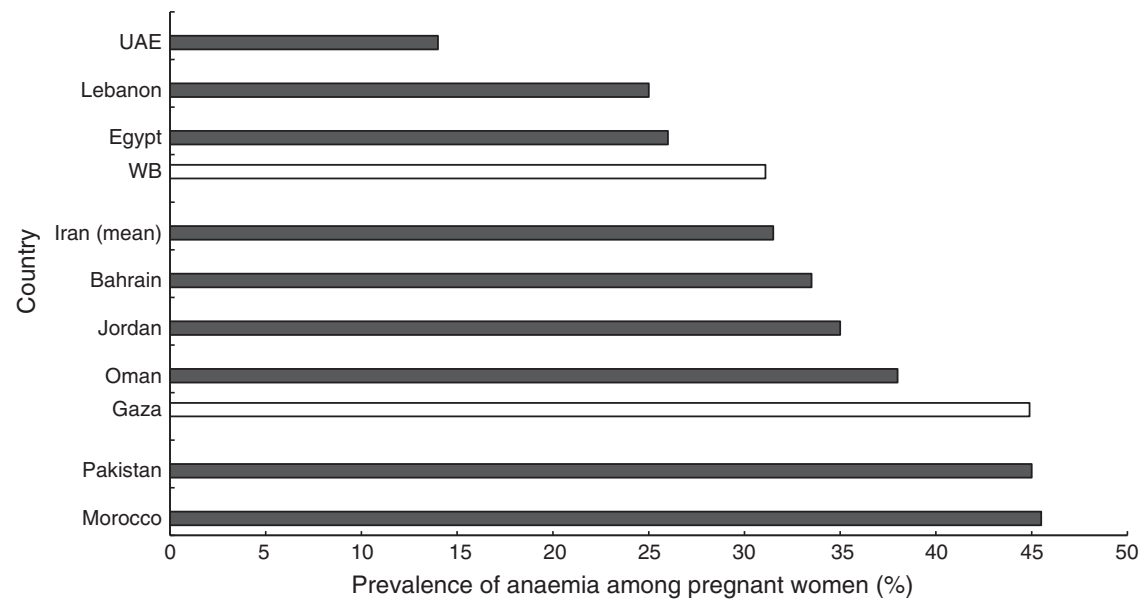

Fig. 2 Anaemia prevalence among pregnant women (UAE, United Arab Emirates): comparison of data from the 2004 survey of the WHO Eastern Mediterranean Region ${ }^{(11)}(\square)$ and the present 2006 UNRWA (United Nations Relief and Works Agency for Palestine Refugees in the Near East) study in the Gaza Strip and the West Bank (WB) ( $\square$ ) 
Although low intake of dietary Fe has been indicated as the main cause of anaemia and the rationale for supplementation programmes, there is currently no scientific evidence that aid programmes comprising flour fortification or food supplementation have improved Fe status of targeted population groups ${ }^{(13)}$.

UNRWA has a long-standing Fe supplementation programme targeting pregnant Palestinian refugee women in the oPt. Coverage has been over $90 \%$ in the past 10 years. Although studies on patient compliance have not been carried out, data from UNRWA pharmacies indicate that on average $90 \%$ of enrolled women regularly receive Fe supplementation as prescribed by UNRWA physicians.

The present study revealed a persistently high prevalence of anaemia despite the existing long-term supplementation programme. The lack of improvement in anaemia prevalence notwithstanding Fe supplementation programmes shows that anaemia cannot be attributed to one cause. It is now accepted that anaemia is not determined by the presence of a single risk factor but by interactions between groups of risk factors, such as poor Fe absorption due to inhibiting dietary substances such as tannins and phytates, high birth rates, short birth intervals, concurrent infections and genetic diseases ${ }^{(11)}$.

There is still debate on the relationship between birth interval and anaemia ${ }^{(14,15)}$, although relevant correlations between anaemia and inter-pregnancy intervals shorter than 6 months ${ }^{(13,16)}$ have been described. This is consistent with the findings of the present survey, where frequent pregnancy was correlated with increased anaemia prevalence.

As expected, the lowest rate of anaemia was observed during the first trimester of pregnancy in both settings and anaemia levels almost doubled in the second and third trimesters of gestation. This variable was the strongest determinant found in the present study: the risk of developing anaemia was threefold higher in the second and third trimesters. Pre-existing anaemia is a risk factor for haemorrhage-related maternal deaths that are one of the main causes of maternal mortality among UNRWA Palestinian refugees ${ }^{(17)}$.

Although Fe metabolism was not studied, the high anaemia prevalence observed combined with epidemiological evidence from previous studies ${ }^{(3)}$ supports $\mathrm{Fe}$ deficiency as the most relevant aetiological factor among pregnant Palestinian refugee women in the oPt. The present survey demonstrated a statistical correlation between anaemia, trimester of pregnancy and parity, with a particularly high risk of developing anaemia in the later stages of pregnancy. This suggests a condition triggered by a pregnancy-induced increased metabolic requirement rather than the consequence of chronically severe micronutrient deficiency. However, the high prevalence rates observed support the hypothesis that concurrent factors such as subclinical micronutrient deficiency, genetic traits and exposure to toxic agents could play a role in making women more prone to developing clinical anaemia during pregnancy.

Although the survey offers enlightening hints on the correlation between biological/social determinants and anaemia prevalence, a study on aetiology including $\mathrm{Fe}$ metabolism was not conducted and therefore causal relationships in this setting cannot be found. Further studies are necessary to examine the relative risk of developing anaemia by cause (toxic, nutritional or genetic).

\section{Acknowledgements}

This research received no specific grant from any funding agency in the public, commercial or not-for-profit sector. Each author has seen and approved the contents of the submitted manuscript and declares that there are no conflicts of interest. G.S. revised the paper and analysis; F.R. carried out the analysis; A.K. and H.M. designed the study, supervised data collection and entry, and drafted the paper. We would like to acknowledge the support provided by the chiefs of the Field Health Programmes in the Gaza Strip and the West Bank, the field laboratory services officers, the field nursing officers, medical officers, senior staff nurses, midwives, professional nurses, laboratory technicians and clerks, who played a major role in blood testing and the process of referral and data collection. Special thanks to Dr Mohammed Maqadmeh, Field Family Health Officer in the Gaza Strip, and to Dr Elias Habash, Field Family Health Officer in the West Bank, for supervising the process of data collection and entry. We would also like to thank Dr Yousef Shahin, Head of the Health Information System, and Ms Wafa'a Zeidan, Assistant Statistician, for their help with data compilation and analysis; and $\mathrm{Mr}$ Ahmad Al-Natour, Senior Laboratory Services Officer at the HQ.

\section{References}

1. United Nations Relief and Works Agency for Palestine Refugees (2003) Impact of the Humanitarian Crisis in the Occupied Palestinian Territory on People and Services. Amman: UNRWA Health Department.

2. Abdeen Z, Greenough G, Shahin M \& Tayback M (2002) Nutritional Assessment of the West Bank and Gaza Strip. CARE and UNAID Emergency Medical Assistance Project. http://www.reliefweb.int/rw/RWFiles2003.nsf/FilesByRWDoc UNIDFileName/ACOS-64D76G-care-opt-02jan.pdf/\$File/careopt-02jan.pdf (accessed July 2009).

3. Yip R (1994) Iron deficiency: contemporary scientific issues and international programmatic approaches. J Nutr 124, Suppl. 8, S1479-S1490.

4. Seal AJ, Creeke PI, Mirghani Z, Abdalla F, McBurney RP, Pratt LS, Brookes D, Ruth LJ \& Marchand E (2005) Iron and vitamin A deficiency in long-term African refugees. $J$ Nutr 135, 808-813.

5. Dunbar S (1984) Malnutrition and anaemia among Somali refugee children in long term camps. Disaster $\mathbf{8}$, 174-177.

6. Madi H (2001) Anaemia among Palestine refugee pregnant women. Paper presented 129th Annual Meeting 
of APHA, Atlanta, GA, USA, 21-25 October 2001, abstract 23219.

7. United Nations Relief and Works Agency for Palestine Refugees (2005) Prevalence of Anaemia among Pregnant Women, Nursing Mothers and Children 6-36 months of Age (A Follow up Study). Amman: UNRWA Health Department.

8. Reveiz L, Gyte GML \& Cuervo LG (2007) Treatments for iron-deficiency anaemia in pregnancy. Cochrane Database Syst Rev issue 2, CD003094.

9. World Health Organization/UNICEF/United Nations University (2001) Iron Deficiency Anaemia: Assessment, Prevention, and Control. A Guide for Programme Managers. Geneva: WHO.

10. McLean E, Cogswell M, Egli I, Wojdyla D \& De Benoist B (2007) Worldwide prevalence of anaemia in preschool aged children, pregnant women and non-pregnant women of reproductive age. In Nutritional Anaemia, pp. 3-12 [K Kraemmer and MB Zimmerman, editors]. Basel: Sight and Life Press.

11. Bagchi K (2004) Iron deficiency anaemia - an old enemy. East Mediterr Health J 10, 754-760.
12. Bocco R, Brunner M, El Haj TA, Al Husseini J, De Martino L, Khalidi A \& Lapeyre F (2006) Palestinian Public Perceptions. Report X - November 2006. Geneva: Graduate Institute of Development Studies (IUED), University of Geneva.

13. Palestine National Authority/World Health Organization/ UNICEF (2005) The State of Nutrition: West Bank and Gaza Strip. A Comprehensive review of Nutrition of West Bank and Gaza Strip. http://www.who.int/hac/crises/international/ wbgs/oPt_Review_of_nutrition_situation_June2005.pdf (accessed July 2009).

14. Dewey KG \& Cohen RJ (2007) Does birth spacing affect maternal or child nutritional status? A systematic literature review. Matern Child Nutr 3, 151-173.

15. Conde-Agudelo A, Rosas Bermudez A \& Kafury-Goeta AC (2007) Effects of birth spacing on maternal health. Am J Obstet Gynecol 196, 297-308.

16. Conde-Agudelo A \& Belizan JM (2000) Maternal morbidity and mortality associated with interpregnancy interval: cross sectional study. BMJ 321, 1255-1259.

17. United Nations Relief and Works Agency for Palestine Refugees (2006) Annual Report of the Department of Health. Amman: UNWRA. 